\title{
Hyperthermia treatment of cancer cells by the application of targeted silk/iron oxide composite spheres.
}

Kamil Kucharczyk ${ }^{\mathrm{a}, \mathrm{b}}$, Katarzyna Kaczmarek ${ }^{\mathrm{c}}$, Arkadiusz Jozefczak ${ }^{\mathrm{c}}$, Mariusz Slachcinski ${ }^{\mathrm{d}}$, Andrzej Mackiewicz ${ }^{\mathrm{a}, \mathrm{b}}$, Hanna Dams-Kozlowska ${ }^{\mathrm{a}, \mathrm{b},{ }^{*}}$

${ }^{\text {a }}$ Chair of Medical Biotechnology, Poznan University of Medical Sciences

${ }^{b}$ Department of Diagnostics and Cancer Immunology, Greater Poland Cancer Centre, Poznan

${ }^{c}$ Chair of Acoustics, Faculty of Physics, Adam Mickiewicz University, Poznan, Poland

${ }^{d}$ Faculty of Chemical Technology, Institute of Chemistry and Technical Electrochemistry, Poznan University of Technology, Poznan, Poland

\section{* Corresponding author:}

Hanna Dams-Kozlowska, PhD

Department of Diagnostics and Cancer Immunology,

Greater Poland Cancer Centre,

15 Garbary St.

61-866 Poznan, Poland

Tel.: +48618850874

Fax.: +48618528502

Email: hanna.dams-kozlowska@wco.pl 


\section{Abstract}

Magnetic iron oxide nanoparticles (IONPs) are one of the most extensively studied materials for theranostic applications. IONPs can be used for magnetic resonance imaging (MRI), delivery of therapeutics, and hyperthermia treatment. Silk is a biocompatible material and can be used for biomedical applications. Previously, we produced spheres made of H2.1MS1 bioengineered silk that specifically carried a drug to the Her2-overexpressing cancer cells. To confer biocompatibility and targeting properties to IONPs, we blended these particles with bioengineered spider silks.

Three bioengineered silks (MS1Fe1, MS1Fe2, and MS1Fe1Fe2) functionalized with the adhesion peptides F1 and F2, were constructed and investigated to form the composite spheres with IONPs carrying a positive or negative charge. Due to its highest IONP content, MS1Fe1 silk was used to produce spheres from the H2.1MS1:MS1Fe silk blend to obtain a carrier with cell-targeting properties. Composite H2.1MS1:MS1Fe1/IONP spheres made of silks blended at different ratios were obtained. Although the increased content of MS1Fe1 silk in particles resulted in an increased affinity of the spheres to IONPs, it decreased the binding of the composite particles to cancer cells. The H2.1MS1:MS1Fe1 particles prepared at a ratio of 8:2 and loaded with IONPs exhibited the ability to bind to the targeted cancer cells similar to the control spheres without IONPs. Moreover, when exposed to the alternating magnetic field, these particles generated 2.5 times higher heat. They caused an almost three times higher percentage of apoptosis in cancer cells than the control particles.

The blending of silks enabled the generation of cancer-targeting spheres with a high affinity for iron oxide nanoparticles, which can be used for anti-cancer hyperthermia therapy.

Keywords: silk, spheres, iron oxygen nanoparticles, hyperthermia, drug carrier, cancer 


\section{Introduction}

Despite the development of diagnostic techniques and multiple novel therapies, the death rate of cancer patients has not changed substantially for decades [1]. Conventional cancer treatment includes surgery, radiotherapy, and chemotherapy. Although chemotherapy is often a first-line therapeutic approach for the treatment of a variety of cancer types, it may damage healthy tissues, leading to irreversible side effects. For example, the highly effective anti-cancer drug doxorubicin (Dox) [2, 3] can cause long-term and potentially lethal cardiovascular toxicity, which may occur many years after chemotherapy $[2,4,5]$. Additionally, to avoid undesirable side effects, chemotherapy dosages are limited, which can ultimately lead to insufficient destruction of cancer. Moreover, according to the World Health Organization (WHO), the early detection of cancer significantly increases the chances for successful treatment (https://www.who.int/cancer/detection/en/). To overcome these limitations, it is necessary to improve the diagnostic techniques and design a drug delivery system that can transport and release chemotherapeutics directly at the tumor site.

The recently developed nanomedicine theranostic platform, which combines specific targeted therapy based on specific diagnostics, has become a promising step in the improvement of cancer therapy efficiency $[6,7]$. This system allows for the simultaneous implementation of diagnostic and therapeutic strategies. Several essential theranostic tools is currently under investigation, such as particles based on quantum dots, gold, carbon (graphene oxide, carbon nanotubes), polymeric liposomes, micelles, dendrimers, biodegradable polymers and superparamagnetic iron oxide [8-10]. Magnetic iron oxide nanoparticles (IONPs) have been extensively investigated for their application in magnetic resonance imaging (MRI) [11] and as carriers of therapeutic agents against cancer cells [12-16]. The anti-cancer activity of IONPs is also based on hyperthermia generation [17]. The application of an alternating magnetic field leads to the thermal activity of IONPs, which causes the 
selective disruption of tumor cells. Due to the activation of heat shock proteins, healthy cells exhibit better tolerance to high temperature than tumor cells [18]. The potential application of IONPs as agents for hyperthermia against cancer cells has been demonstrated in various studies $[19,20]$. On the other hand, the in vivo administration of iron oxide particles may be restricted by their toxicity and nanotoxicity [21]. It was already reported that a high concentration of iron ions might cause neuronal damage in certain brain areas [22]. Pisanic et al. showed that the accumulation of IONPs resulted in the inhibition of the growth of neural cells [23]. To limit their toxicity, the IONPs can be combined with various materials obtaining more biocompatible and tunable composite structures.

The extraordinary properties of silk make it a suitable material for application in cancer treatment. Moreover, the implementation of genetic engineering and biotechnological processes enables the extension of the potential application of bioengineered spider silk proteins. Biocompatibility, biodegradability, and the ability to self-assemble into various morphological forms are the key attributes of silk [24-27]. Among silk fibers, films, scaffolds, hydrogels, spherical microparticles and nanoparticles demonstrate the greatest applicability as drug carriers. The silk fibroin obtained from Bombyx mori cocoons was successfully used for the production of drug-delivering nanoparticles $[28,29]$. The efficient binding and release of therapeutic molecules was reported for nanoparticles made of bioengineered eADF4(C16) silk based on the ADF4 protein of the Araneus diadematus spider [30-32] and MS1 and MS2 silks based on the Nephila clavipes proteins MaSp1 and MaSp2, respectively [33, 34]. Moreover, the bioengineering of spider silk enables modification of its sequence to functionalize the material with new features or functions [35]. This functionalization can be achieved by changing the amino acid sequence of silk or by addition of functional peptides. These modifications may change the isoelectric point of silk protein $[36,37]$, enhance the binding 
and cellular uptake of silk nanoparticles $[38,39]$ or enable the binding of therapeutic nucleic acids to silk particles $[40,41]$.

The possibility of combining silk and iron oxide nanoparticles has been previously shown. Composite magnetic spheres have been obtained from both silk fibroin $[42,43]$ and the bioengineered spider silk EMS2 [44]. The EMS2 silk was constructed by the addition of glutamic acid into a monomer unit of MS2 silk [37]. EMS2/IONP composite spheres demonstrated good magnetic properties and morphology; however, the $\mathrm{Fe}^{3+}$ ion content was relatively low [44]. The IONPs tended to aggregate and formed clusters on the surface of composite spheres [44]. Moreover, studies by Florczak et al. showed that the increasing content of functionalized MS2 silk in the functionalized MS1/MS2 blended silk particles caused reduction in the efficiency of their binding to cancer cells, which suggested a crucial role of MS1 protein in this process [45]. Considering all these aspects, we decided to investigate a new therapeutic system based on functionalized MS1 silk proteins.

In this study, we produced and characterized a composite material made of IONPs and a blend of two types of functionalized MS1 silks: i) one containing the metal-binding peptides KSLSRHDHIHHH and/or SVSVGMKPSPRP (named Fe1 and Fe2, respectively, in this study) and ii) the other containing the Her2-binding peptide H2.1 [38]. The results of previous studies demonstrated that the Fe1 and Fe2 peptides have the potential for application as adhesion molecules. These peptides were investigated in terms of their binding to inorganic targets, such as silica [46], gallium nitride [47], hydroxyapatite [48], iron-platinum nanoparticles [49] and other metal compounds [50]. In addition, the functionalization of MS1 silk with the H2.1 peptide enabled the accumulation of H2.1MS1 spheres in Her2-positive cancer cells [38]. Overexpression of the Her2 receptor can be observed in more than $20 \%$ of breast carcinomas [51]. In combination with its low expression in healthy tissues, the Her2 molecule is an excellent target for specific anticancer treatment. 
The aim of this study was to generate a targeted silk-based delivery system that efficiently transports iron oxide nanoparticles (IONPs) into cancer cells. We have incorporated IONP into spheres made of several variants of silk. Selected H2.1MS1: MS1Fe1/IONP particles bound to targeted Her2-overexpressing cancer cells and, when exposed to an alternating magnetic field, generated heat leading to cell apoptosis.

\section{Experimental}

\subsection{Construction of the expression plasmids}

The construction of the expression plasmids pETNX-MS1 and pETNX-H2.1MS1 was described previously [38]. For this study, we used the plasmids pET30a-MS16xFe1 and pET30a-MS16xFe2, generously provided by Professor David Kaplan (Tufts University, Medford, Massachusetts, USA). Both plasmids contained 6 repeated MS1 silk sequences based on the MaSp1 protein of $N$. clavipes that were functionalized with the metal-binding domain Fe1 or Fe2. The MS16xFe1 and MS16xFe2 sequences were cleaved out using the NheI and SpeI restriction enzymes and cloned into the NheI and SpeI restriction sites of the pETNX expression vector to obtain pETNX-MS16xFe1 and pETNX-MS1Fe2, respectively. The final plasmids were constructed by ligation of the MS16xFe1 and MS16xFe2 inserts into the SpeI restriction sites of the previously obtained constructs pETNX-MS16xFe1 and pETNX-MS16xFe2, respectively, and ligation of the MS16xFe2 insert into the SpeI restriction site of the pETNX-MS16xFe1 plasmid as indicated in Fig. 1. The sequences of the obtained plasmids were confirmed by sequencing at the Adam Mickiewicz University Core Facility in Poznan. Enzymes for digestion and ligation were purchased from Fermentas (Thermo Fisher Scientific Inc., Waltham, MA) and New England Biolabs, Inc. (Ipswich, MA), respectively.

\subsection{Production and purification of bioengineered spider silks}


The Escherichia coli strain BLR (Novagen, Madison, WI) was transformed using the pETNX-MS1, pETNX-H2.1MS1, pETNX-(MS1Fe1)2, pETNX-(MS1Fe2) 2 and pETNXMS1Fe1MS1Fe2 expression plasmids to obtain the MS1, H2.1MS1, MS1Fe1, MS1Fe2 and MS1Fe1Fe2 proteins, respectively. The proteins were produced in a Bioflo 4000 fermenter (New Brunswick Scientific, Edison, NJ) under the conditions described previously [38]. The proteins were purified using the thermal denaturation method $(80 / 20)$ as performed in previous studies [38]. The silk proteins were precipitated using $20 \%$ ammonium sulfate for MS1 and H2.1MS1 and 25\% for the MS1Fe1, MS1Fe2, and MS1Fe1Fe2 silks. The protein concentration was measured by UV spectroscopy (Nanodrop 2000, Thermo Fisher Scientific, Inc., Waltham, MA) at a wavelength of $280 \mathrm{~nm}$ and calculated using molar extinction coefficients of 19370 and $43320 \mathrm{M}^{-1} \mathrm{~cm}^{-1}$ for sMS1 and H2.1MS1, respectively, and 17880 $\mathrm{M}^{-1} \mathrm{~cm}^{-1}$ for the MS1Fe1, MS1Fe2, and MS1Fe1Fe2 proteins. The molecular weights of MS1, H2.1MS1, MS1Fe1, MS1Fe2 and MS1Fe1Fe2 were 34.31, 41.68, 35.04, 34.52 and 34.78 $\mathrm{kDa}$, respectively. Electrophoretic analysis was performed using a 12.5\% SDS-PAGE gel, and the proteins were stained with colloidal blue (Roti-Blue) (Carl Roth, Karlsruhe, Germany).

\subsection{Cell cultures}

SKBR3 human breast cancer cells that overexpressed Her2 (ATCC, Manassas, VA) and MSU1.1 human fibroblast cells (generously provided by Professor C. Kieda, (CBM, CNRS, Orleans, France)) were used in this study. The cells were maintained in Dulbecco's Modified Eagle Medium (Sigma, St Louis, MO) supplemented with 10\% fetal bovine serum (Sigma, St Louis, MO) and $80 \mu \mathrm{g} / \mathrm{mL}$ gentamycin (KRKA, Novo Mesto, Slovenia). Cells were grown at $37^{\circ} \mathrm{C}$ in a humidified atmosphere containing $5 \% \mathrm{CO}_{2}$.

\subsection{Sphere preparation}


Spheres were produced by salting out using potassium phosphate buffer. Fifty microliters of silk solution at a concentration of $2 \mathrm{mg} / \mathrm{mL}$ was added to $50 \mu \mathrm{L}$ of iron oxide nanoparticles (IONPs; $2 \mathrm{mg} / \mathrm{mL}$; Chemicell GmbH, Berlin, Germany) with positive or negative charge and thoroughly mixed with $1000 \mu \mathrm{L}$ of $2 \mathrm{M}$ potassium phosphate buffer (Sigma, St Louis, MO) at $\mathrm{pH}$ 8. The samples were incubated overnight, centrifuged at 10000 $\mathrm{x} \mathrm{g}$ for $20 \mathrm{~min}$ and then rinsed five times with ultrapure water.

To study the properties of the blended spheres, H2.1MS1 and MS1Fe1 silks were combined at different weight ratios (10:0, 8:2, 5:5, 2:5, and 0:10 H2.1MS1:MS1Fe1, respectively), and then spheres were produced as follows: $50 \mu \mathrm{L}$ of a solution of blended silks at a concentration of $2 \mathrm{mg} / \mathrm{mL}$ was added to $50 \mu \mathrm{L}$ of a negatively charged IONP suspension at a concentration of $2 \mathrm{mg} / \mathrm{mL}$ and then mixed with $2 \mathrm{M}$ potassium phosphate solution at $\mathrm{pH}$ 8. The spheres were incubated overnight, centrifuged at $10000 \mathrm{xg}$ for $20 \mathrm{~min}$ and then rinsed three times with ultrapure water. Control spheres were prepared as described above except that $10 \mathrm{mM}$ Tris- $\mathrm{HCl}(\mathrm{pH} 7.5)$ was used instead of the IONP suspension. For the cell binding assay, the silks were first conjugated with the ATTO 647N fluorophore (Sigma, St. Louis, MO) following the manufacturer's protocol. For drug loading/release, cytotoxicity and magnetic hyperthermia studies, spheres were prepared using high-pressure syringe pumps as described previously [52]. The solutions of blended silks $(1 \mathrm{mg} / \mathrm{mL})$ with or without IONPs were mixed with $2 \mathrm{M}$ potassium phosphate $(\mathrm{pH} 8)$ at a volume ratio of 1:10. The flow speeds for silk or silk/IONPs and potassium phosphate buffer were 10 and $100 \mu \mathrm{L} / \mathrm{s}$, respectively. The collected suspension of spheres was incubated overnight at room temperature, centrifuged at $10000 \mathrm{x}$ g for $20 \mathrm{~min}$, and then rinsed five times with ultrapure water.

\subsection{Scanning Electron Microscopy (SEM) and Energy Dispersive X-ray Spectroscopy (EDXS)}


The spheres were sonicated using an ultrasonic cell disruptor (Misonix, Inc., Farmingdale, New York), and the sphere suspension was placed on a coverslip and left to airdry. The sample was sputtered with gold under vacuum using a Quorum Sputter Coater Q150T ES (Quorum Technologies, Ringmer, UK) and then analyzed with an SEM (JEOL JSM-7001F, JEOL. Ltd, Tokyo, Japan) at an accelerating voltage of $15 \mathrm{kV}$. Energy-dispersive $\mathrm{X}$-ray spectroscopy of the samples for elemental analysis was performed using an X-Max silicon drift detector (Oxford Instruments, Abingdon, UK) and INCA Energy software (Oxford Instruments Analytical, High Wycombe, UK).

\subsection{Microwave-Induced Plasma with Optical Emission Spectrometry (MIP-OES)}

The composite spheres made of IONPs and H2.1MS1:MS1Fe1/IONP silk blended at various weight ratios $(10: 0,8: 2,5: 5,2: 8,0: 10)$ were analyzed using a Carl Zeiss Echelle spectrometer, model PLASMAQUANT 100 (Carl Zeiss AG, Oberkochen, Germany), with fiber-optical light-guide, photomultiplier tubes (PMTs). The particles were dissolved in 0.5 $\mathrm{mL}$ of concentrated $\mathrm{HNO}_{3}$ and $0.5 \mathrm{~mL}$ of $30 \% \mathrm{HCl}$ in a quartz vessel, sonicated for $4 \mathrm{~min}$ and calibrated to $2 \mathrm{~mL}$. The concentration of iron in the spheres was analyzed in continuous mode using an ultrasonic nebulizer (model NOVA-DUO, Optolab, Warsaw, Poland) with a glass cyclonic spray chamber. The experiment was repeated three times.

\subsection{Sphere binding to the cells}

The SKBR3 human breast cancer cells and MSU1.1 human fibroblasts were washed with PBS and detached using a nonenzymatic cell dissociation solution (Sigma, St Louis, MO). Subsequently, $30 \mu \mathrm{L}$ of ATTO647-labeled spheres at a concentration of $10 \mu \mathrm{g} / \mathrm{mL}$ was added to $1 \times 10^{5}$ SKBR3 or MSU1.1 cells suspended in a $0.5 \%$ BSA/PBS solution and then incubated for $1 \mathrm{~h}$ at $4{ }^{\circ} \mathrm{C}$ in the dark. Next, the cells were rinsed three times with PBS, and the 
binding of the spheres was analyzed using a FACSAria flow cytometer (BD Biosciences Pharmingen, San Jose, CA) and FACSDiva (v6.1.2) software.

\subsection{Drug loading and release study}

The H2.1MS1:MS1Fe1 and H2.1MS1:MS1Fe1/IONP spheres were loaded with doxorubicin (Dox) (Adriamycin, Pfizer Inc., New York City, NY) using the postloading method as described previously [33]. In brief, $50 \mu \mathrm{g}$ of spheres was mixed with $100 \mu \mathrm{g}$ of a drug in a final volume of $300 \mu \mathrm{L}$ and incubated at room temperature overnight with agitation. Next, the spheres were centrifuged, and the absorbance of the supernatant was measured spectrophotometrically at a wavelength of $508 \mathrm{~nm}$ to determine the Dox concentration. The drug concentration was quantified based on the standard curves for doxorubicin. The loading efficiency was calculated using the equation: loading efficiency $(\%)=($ the amount of drug loaded) / (amount of drug before loading) x 100\%. The experiment was performed three times in triplicate.

Dox-loaded spheres were subsequently suspended in $1 \mathrm{~mL}$ of PBS at $\mathrm{pH} 4.5,6$ or 7.4 and incubated at $37{ }^{\circ} \mathrm{C}$ under constant agitation. The samples were centrifuged, and the supernatant was collected at the indicated time points and replaced with fresh buffer at an appropriate $\mathrm{pH}$. The concentration of released Dox was determined spectrophotometrically as described above. The experiment was performed three times in triplicate.

\subsection{Thermogravimetric analysis}

The thermal behavior of H2.1MS1MS1Fe1/IONPs/Dox was studied using Perkin Elmer TGA 4000 analyzer (PerkinElmer, Waltham, MA). $5 \mathrm{mg}$ of sample was measured under a nitrogen atmosphere with a flow rate of $20 \mathrm{~mL} / \mathrm{min}$. The samples were heated from 30 ${ }^{\circ} \mathrm{C}$ to $995^{\circ} \mathrm{C}$ at a heating rate of $10 \%$ min. 


\subsection{Cytotoxicity study}

SKBR3 breast cancer cells $\left(2.5 \times 10^{4} /\right.$ well $)$ were seeded in 96-well plates and incubated overnight. The next day, various concentrations of H2.1MS1:MS1Fe1 and H2.1MS1:MS1Fe1/IONPs silk spheres loaded with Dox were added to the cells and incubated for $4 \mathrm{~h}$. Subsequently, the cells were washed with PBS, and fresh medium was added. After $72 \mathrm{~h}$ of incubation, $50 \mu \mathrm{L}(5 \mathrm{mg} / \mathrm{mL})$ of MTT (3-(4,5dimethylthiazol-2-yl)-2,5-diphenyl tetrazolium bromide; Sigma, St. Louis, MO) solution was added to each well and incubated for $4 \mathrm{~h}$. Next, the insoluble purple formazan was dissolved in $200 \mu \mathrm{L}$ of dimethyl sulfoxide (Sigma, St. Louis, MO). A Victor X3 microplate reader (PerkinElmer, Waltham, MA) was used to measure the absorbance of the solution at a wavelength of $560 \mathrm{~nm}$. The cell viability was calculated in reference to the untreated control cells. The experiment was repeated three times in triplicate.

\subsection{Measurement of temperature upon treatment of spheres with a magnetic field}

To investigate the heating potential of the H2.1MS1:MS1Fe1 and H2.1MS1:MS1Fe1/IONP particles, spheres were subjected to an alternate magnetic field (AMF) study. The compact EASYHEAT (Ambrell Corporation, Scottsville, NY, USA) induction heating system was used as a source of the AMF. The induction heating setup consisted of a high-frequency power supply and a water-cooled heating coil. The sphere suspension $(2 \mathrm{mg})$ in a $15-\mathrm{mL}$ tube was placed centrally inside the induction coil with a length of $60 \mathrm{~mm}$ and five turns with a 56- $\mathrm{mm}$ diameter. The frequency of the alternating magnetic field was $f=356 \mathrm{kHz}$, and the intensity was $H=16.2 \mathrm{kA} / \mathrm{m}$. The temperature variation induced during the experiment was registered by a digital thermometer (FLUOTEMP, Photon Control Inc.) with the optic fiber temperature probe (model FTP-NY2) placed centrally in the sample. 
The samples were treated with a magnetic field for 180 seconds. The experiment was performed three times.

\subsection{Evaluation of the hyperthermia effect}

SKBR3 cells $\left(2 \times 10^{5}\right)$ were seeded on a 6 -cm culture plate and incubated overnight. Next, the control and composite spheres were added at a concentration of $100 \mu \mathrm{g} / \mathrm{mL}$. After $12 \mathrm{~h}$ of incubation, the cells were washed with PBS and detached, and then, magnetic treatment was performed for 5 minutes as described above. Next, to determine the hyperthermia effect, the treated cells were stained with an Annexin V-FITC Apop Kit (Invitrogen, Waltham, Massachusetts, USA) according to the manufacturer's protocol. The cells were analyzed using a FACSAria flow cytometer and FACSDiva (v6.1.2) and FlowJo V10 software. The experiment was repeated three times.

\subsection{Statistics}

To estimate the significant differences between the samples, the analysis of variance (ANOVA) post hoc test with the Bonferroni correction was used. An unpaired t-test was performed to analyze the differences in drug loading efficiency. The results were considered significant if the $p$-value was $\leq 0.05$.

\section{Results}

\subsection{Construction, production, and purification of bioengineered spider silk proteins}

The construction scheme and amino acid sequences of three functionalized spider silk proteins (MS1Fe1, MS1Fe2, and MS1Fe1Fe2) are shown in Fig. 1A. A 13-mer of MS1 silk was used as a control (sMS1). The bioengineered proteins were expressed in E. coli and purified using the thermal denaturation method. The yields of purification were approximately 
as follows: $1.9,2.4,1.2$, and $1.3 \mathrm{mg}$ per $1 \mathrm{~g}$ of bacterial pellet for sMS1, MS1Fe1, MS1Fe2, and MS1Fe1Fe2, respectively. SDS-PAGE analysis showed the high quality of the proteins and confirmed their expected molecular masses of approximately $35 \mathrm{kDa}$ (Fig. 1B). The quality and molecular mass of the H2.1MS1 protein was analyzed previously [38].

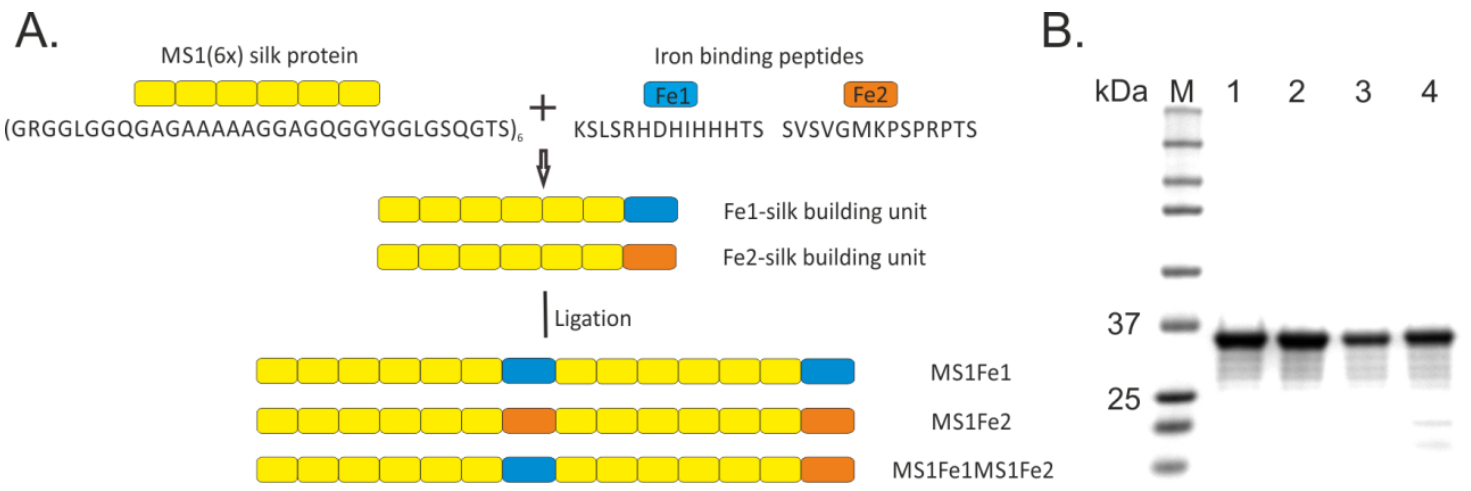

Fig. 1. Schematic construction and analysis of bioengineered spider silk proteins functionalized with the metal-binding peptides Fe1 and Fe2. (A) The amino acid sequences of the repetitive motif of silk and the peptides Fe1 and Fe2 are shown. (B) Electrophoretic analysis of silk proteins by $12.5 \%$ SDS-PAGE: M, molecular weight protein marker (Precision Plus Protein Kaleidoscope, Bio-Rad, California, USA); 1, sMS1; 2, MS1Fe1; 3, MS1Fe2; 4, MS1Fe1Fe2.

\subsection{Production of bioengineered silk/iron oxide composite spheres}

The composite spheres were formed upon mixing the silk solution and positively or negatively charged iron oxide nanoparticles with concentrated potassium phosphate buffer (Fig. 2). The SEM analysis demonstrated that the functionalization of spider silk with the metal binding peptides $\mathrm{Fe} 1$ and $\mathrm{Fe} 2$ did not impede sphere formation (Fig. 2). The mixing of sMS1 silk with both positively and negatively charged IONPs resulted in compact aggregate structures covered with iron oxide nanoparticles. According to the EDXS examination, the functionalization of spider silk with $\mathrm{Fe} 1$ and $\mathrm{Fe} 2$ increased the capacity of the spheres for binding iron oxide nanoparticles in comparison with spheres made of control sMS1 silk (Fig. 
2). The IONPs could be observed as aggregated bumps on the surface of the composite spheres. The Fe1 peptide was more effective in the binding of IONPs than the Fe2 peptide, as indicated by the elemental analysis using EDXS. The SEM image analysis showed that the addition of IONPs with negative charge resulted in the formation of particles that were more separated and had a more spherical morphology than the IONPs with positive charge. Moreover, the efficiency of the binding of negatively charged IONPs was higher than that of positively charged IONPs.

Due to their highest iron oxide nanoparticle binding capacity and most favorable morphology, we chose the MS1Fe1 silk protein and negatively charged IONPs for further analysis. 

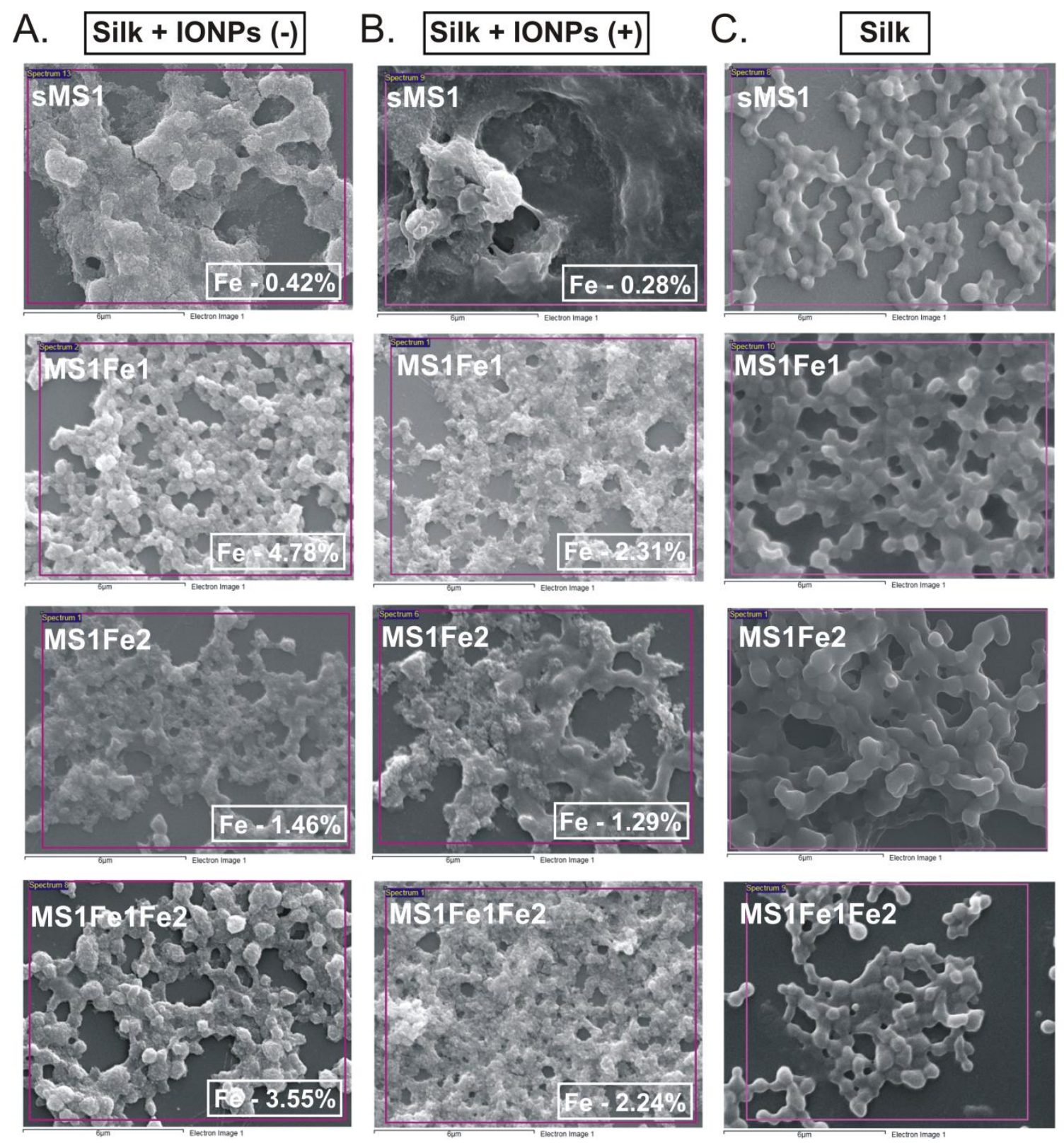

Fig. 2. SEM images and EDXS analysis of sMS1, MS1Fe1, MS1Fe2, and MS1Fe1Fe2

control and composite spheres. Silk solution at a concentration of $2 \mathrm{mg} / \mathrm{mL}$ was mixed with IONPs $(2 \mathrm{mg} / \mathrm{mL})$ with negative (A) or positive (B) charge prior to sphere formation upon salting out with $2 \mathrm{M}$ potassium phosphate buffer. For control spheres, $10 \mathrm{mM}$ Tris- $\mathrm{HCl}$ was used instead of IONPs (C). Scale bar, $6 \mu \mathrm{m}$. The white squares indicate the iron percentage content according to the EDXS analysis. 


\subsection{Production and iron oxide nanoparticle content in composite blended spheres}

The next step involved the investigation of spheres composed of the blend of two silks: i) H2.1MS1 silk (MS1 silk functionalized with the peptide H2.1 that binds to Her2) and ii) MS1Fe1 silk. The silks were blended at different weight ratios (10:0, 8:2, 5:5, 2:8, and 0:10 H2.1MS1:MS1Fe1, respectively), mixed with negatively charged IONPs and used for sphere formation. First, these spheres were analyzed in terms of their affinity for iron oxide nanoparticles. As expected, we observed an increasing concentration of iron ions in samples with more MS1Fe1 silk than H2.1MS1 silk in the composite blended particles (Table 1).

Table 1 Iron ion content in the composite blended spheres. The spheres were obtained by mixing $2 \mathrm{M}$ potassium phosphate with $\mathrm{H} 2.1 \mathrm{MS} 1$ and MS1Fe1 silks blended at various weight ratios $(10: 0,8: 2,5: 5,2: 8$, and $0: 10)$ in the presence of iron oxide nanoparticles. The results represent the mean value and SD of three experiments.

\begin{tabular}{ccc}
\hline $\begin{array}{c}\text { Ratio of H2.1MS1:MS1Fe1 } \\
\text { silks in composite } \\
\text { blended spheres }\end{array}$ & $\begin{array}{c}\text { Iron content } \\
(\mu \mathrm{gg} \text { Fe/ } \mu \mathrm{g} \\
\text { spheres })\end{array}$ & +/-SD \\
\hline $\mathbf{1 0 : 0}$ & 0.064 & 0.03 \\
$\mathbf{8 : 2}$ & 0.098 & 0.02 \\
$\mathbf{5 : 5}$ & 0.112 & 0.01 \\
$\mathbf{2 : 8}$ & 0.125 & 0.01 \\
$\mathbf{0 : 1 0}$ & 0.140 & 0.02 \\
\hline
\end{tabular}

\subsection{Cell binding analysis of composite blended silk spheres}

Next, the composite blended particles were incubated with Her2-positive cells (SKBR3) and control fibroblasts (MSU1.1) and then analyzed using flow cytometry. All variants of spheres containing the Her2-binding peptide demonstrated affinity for Her2overexpressing cells (Fig. 3). The percentage of binding was dependent on the amount of H2.1MS1 and decreased with decreasing percentage of this silk in the blends (Fig. 3A). All 
sphere variants containing Her2 peptide exhibited approximately $6 \%$ nonspecific binding to MSU1.1 control cells. The composite spheres that did not contain H2.1MS1 silk did not bind to either cancer or control cells (Fig. 3).
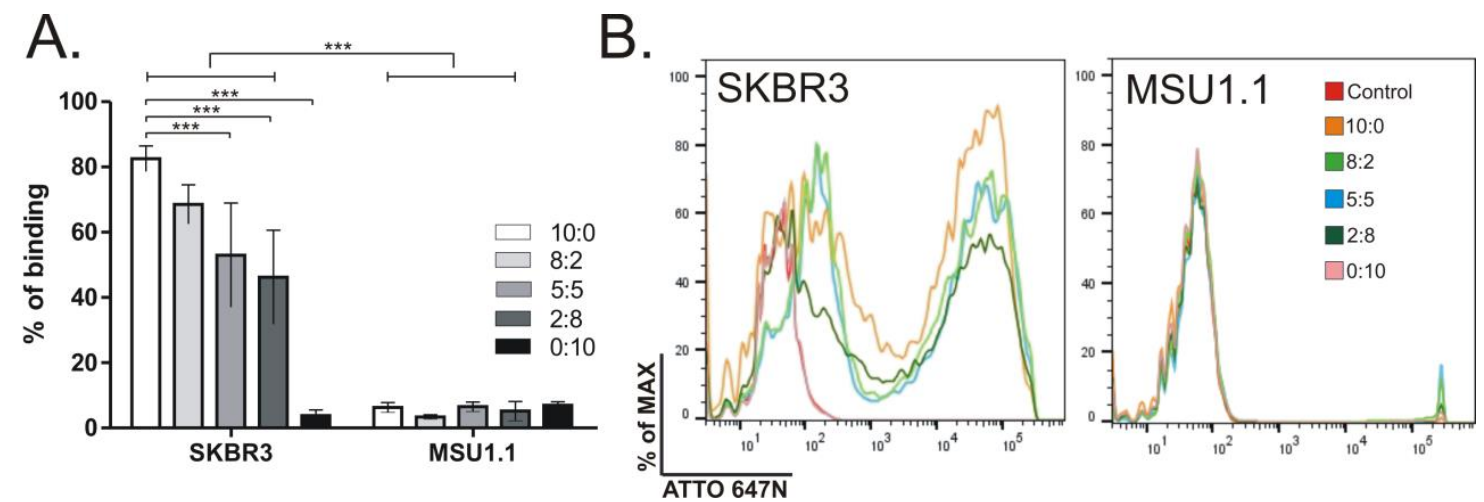

Fig. 3. Flow cytometric analysis of the cell binding of composite blended spheres. Her2positive SKBR3 and control MSU1.1 cells were incubated with spheres composed of a H2.1MS1:MS1Fe1 blend (at various weight ratios) and IONPs. (A) Percentage of binding of the sphere variants to cancer cells and control fibroblasts. The means and standard deviations of three experiments are shown. $* *$ indicates statistical significance with $\mathrm{p}<0.01$; *** indicates statistical significance with $\mathrm{p}<0.001$. (B) Representative graphs of the flow cytometric analysis of the composite blended spheres. Non-treated cells were the control.

\subsection{Morphology of composite blended spheres}

The SEM analysis indicated that the blending of silks did not interfere with the production of the composite spheres (Fig. 4A). The IONPs were observed as aggregates on the surface of silk spheres. The particles made of the H2.1MS1:MS1Fe1 blend (at a ratio of 8:2) were less covered by IONPs (Fig. 4A) than spheres containing only MS1Fe1 silk (Fig. 4B). The results were in agreement with the spectrometry analysis of iron ion content in composite spheres (Table 1). 
Due to their highest iron ion content and affinity for SKBR3 cells that was comparable to that of the H2.1MS1 particles, the H2.1MS1:MS1Fe1 spheres blended at an 8:2 ratio were selected for further study.
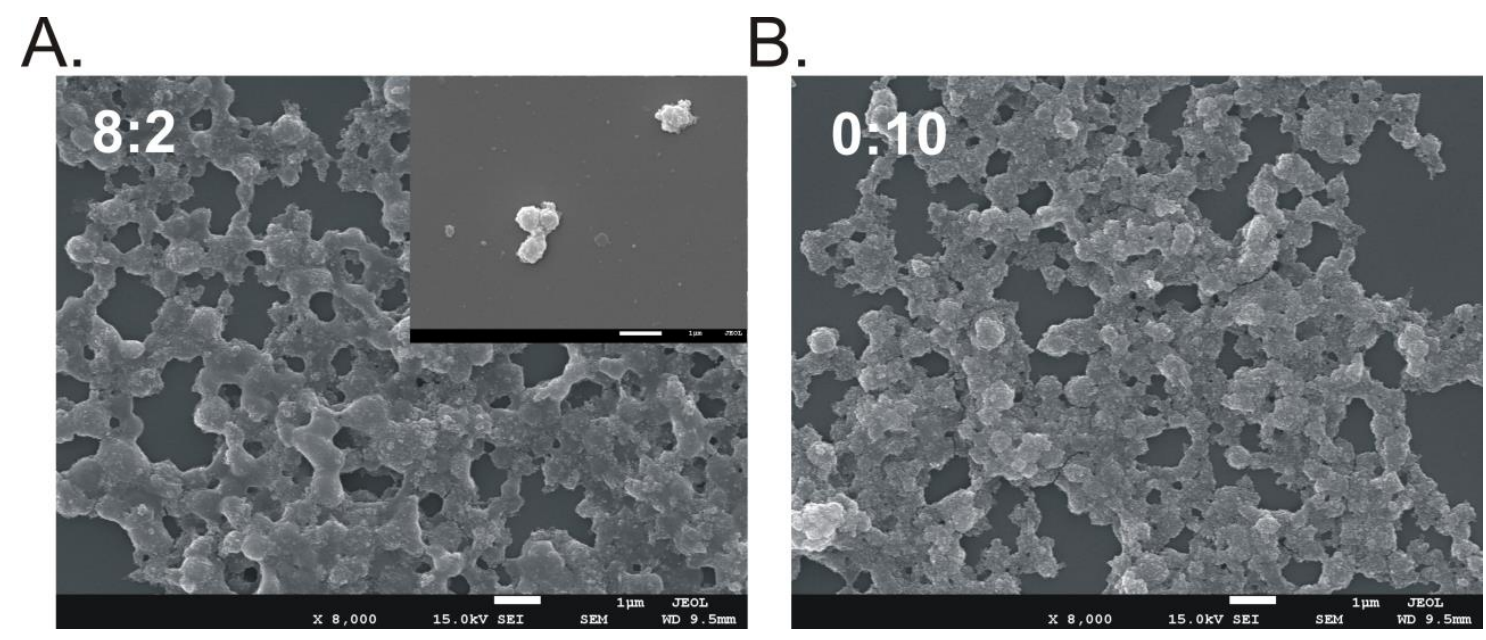

Fig. 4. SEM images of composite spheres. Spheres were made of IONPs (-) and A) a H2.1MS1:MS1Fe1 blend prepared at 8:2 or B) MS1Fe1 silk. The silk solutions $(2 \mathrm{mg} / \mathrm{mL})$ were mixed with IONPs $(-)(2 \mathrm{mg} / \mathrm{mL})$, and then, the composite spheres were prepared in the presence of $2 \mathrm{M}$ potassium phosphate buffer. Scale bar, $1 \mu \mathrm{m}$.

\subsection{Drug loading and release study using composite blended spheres}

The ability of composite blended spheres to serve as drug carriers was examined by performing doxorubicin (Dox) loading/release studies. The efficiency of Dox loading into H2.1MS1:MS1Fe1/IONP spheres was approximately $1.3 \mathrm{x}$ higher than that into H2.1MS1:MS1Fe1 particles without IONPs, which was significant (Fig. 5A). Although the functionalization of silk with binding domains significantly decreased the binding of Dox by MS1Fe1 silk, the presence of IONPs compensated for this difference. 
A.

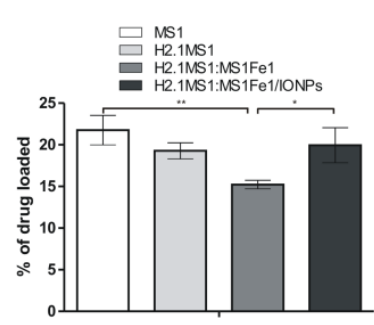

B.

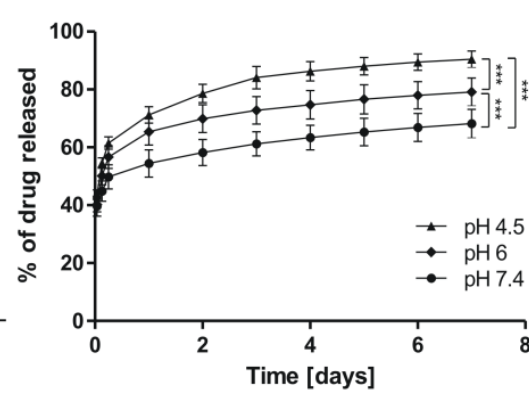

C. H2.1MS1:MS1Fe1//ONPs/Dox

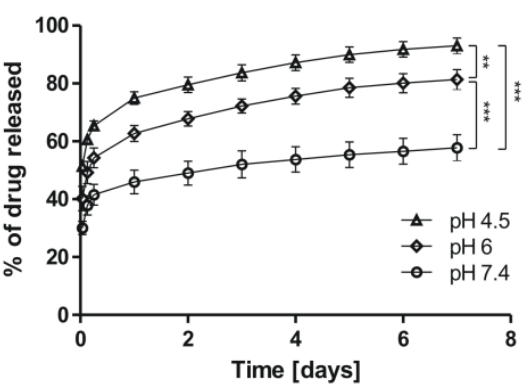

Fig. 5. Doxorubicin loading and release. (A) Efficiency of Dox loading into silk sphere variants. The means and standard deviations of three independent experiments are shown. Doxorubicin was released from blended (B) and (C) composite blended spheres over 7 days in PBS at $\mathrm{pH} 7.4,6$ or 4.5 at $37^{\circ} \mathrm{C}$. Dox release was measured on the first day after 1,3 , and $6 \mathrm{~h}$ of incubation and then after every $24 \mathrm{~h}$. The mean and standard deviation of three experiments are shown. ${ }^{* *}$ indicates statistical significance with $\mathrm{p}<0.01 ; * *$ indicates statistical significance with $\mathrm{p}<0.001$

The release of incorporated doxorubicin was performed at $37{ }^{\circ} \mathrm{C}$ in PBS at a pH of 7.4, 6 or 4.5 over 7 days. For both types of spheres, we observed $\mathrm{pH}$-dependent release profiles. Incubation in an acidic environment resulted in faster release of drug from the particles than that under neutral conditions (Fig. 5B, C).

The blended spheres that contained IONPs released approximately 1.2 times less drug at a $\mathrm{pH}$ of 7.4 after 7 days of incubation than the blended particles. At a $\mathrm{pH}$ of 4.5 , approximately 1.1 times higher Dox release was observed from H2.1MS1:MS1Fe1/IONPs than from particles without IONPs (Fig. 5B, C).

\subsection{Thermogravimetric analysis of composite blended spheres}

The thermal behavior of the composite blended spheres loaded with Dox was investigated by performing thermogravimetric (TGA) analysis (Fig. 6). The initial weight loss 
of $\mathrm{H} 2.1 \mathrm{MS} 1: \mathrm{MS} 1 \mathrm{Fe} 1 / \mathrm{IONPs} / \mathrm{Dox}$ particles was approximately $8 \%$ until the $100{ }^{\circ} \mathrm{C}$ what can be attributed to solvent evaporation. The weight remained relatively stable until the temperature reached $250{ }^{\circ} \mathrm{C}$. The second major weight loss was observed at the temperature range of $250-750{ }^{\circ} \mathrm{C}$, and it for approximately $75 \%$ (Fig. 6).

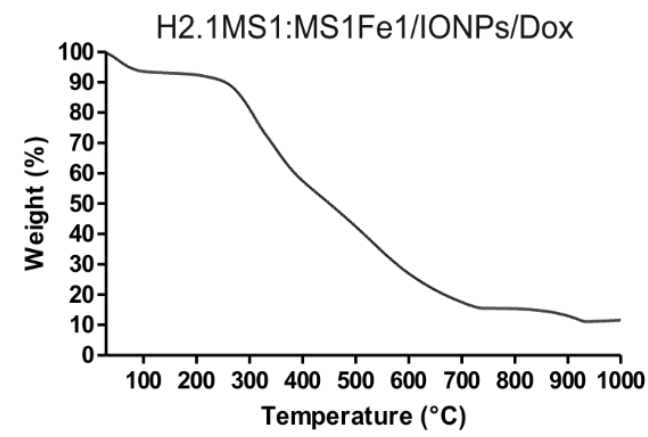

Fig. 6: TGA thermogram of composite blended spheres loaded with Dox. The H2.1MS1:MS1Fe1/IONPs/Dox particles were heated over the temperature range of $30-995{ }^{\circ} \mathrm{C}$ at a constant rate of $10^{\circ} \mathrm{C} / \mathrm{min}$.

\subsection{Cytotoxic effect of Dox-loaded composite blended spheres}

SKBR3 cells were incubated with different concentrations of H2.1MS1:MS1Fe1 and H2.1MS1:MS1Fe1/IONP spheres loaded with Dox. The composite blended spheres reduced the viability of Her2-positive breast cancer cells slightly more than the blended particles (without IONPs) (Fig. 7). The significant difference between spheres was indicated at the highest particle concentrations -12.5 and $25 \mu \mathrm{g} / \mathrm{mL}$. 


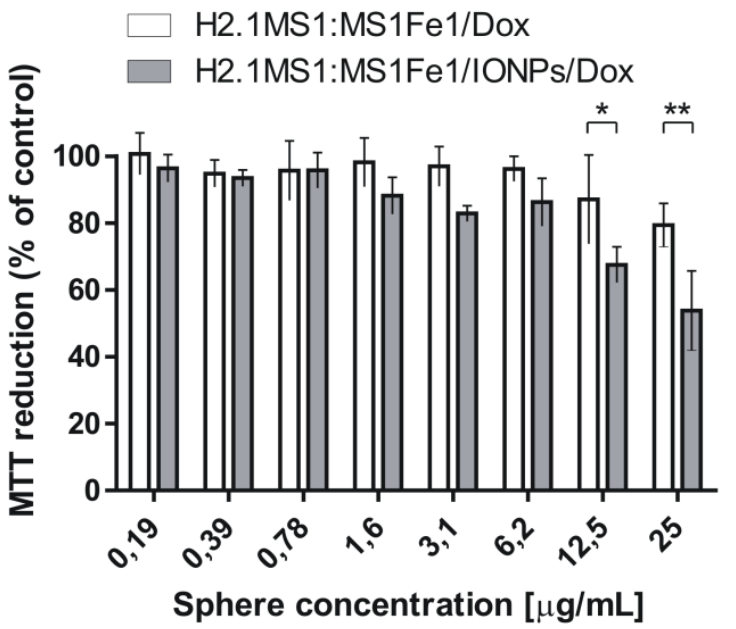

Fig. 7. Cytotoxicity studies of Dox-loaded spheres measured by the MTT assay. SKBR3 cells were incubated with various concentrations of H2.1MS1:MS1Fe1 and H2.1MS1:MS1Fe1/IONP Dox-loaded spheres for $4 \mathrm{~h}$ and then cultured for $72 \mathrm{~h}$. The $\%$ of MTT reduction was calculated in reference to nontreated control cells. The means and standard deviations of three experiments are shown. * indicates statistical significance with $\mathrm{p}$ $<0.05 ; * *$ indicates statistical significance with $\mathrm{p}<0.01$.

\subsection{Thermal properties of composite blended spheres}

An alternating magnetic field was used to assess the capability of spheres to generate temperature increase. Under magnetic treatment, the H2.1MS1:MS1Fe1/IONP spheres exhibited an increase in temperature that was 2.5 times higher than that of the particles without IONPs (Fig. 8). The H2.1MS:MS1Fe1 spheres generated heat at the same level as pure water which acted as a reference medium. Pure water does not have magnetic properties and cannot itself generate heat. The registered for water temperature increase results from not ideal adiabatic condition during experiments. 


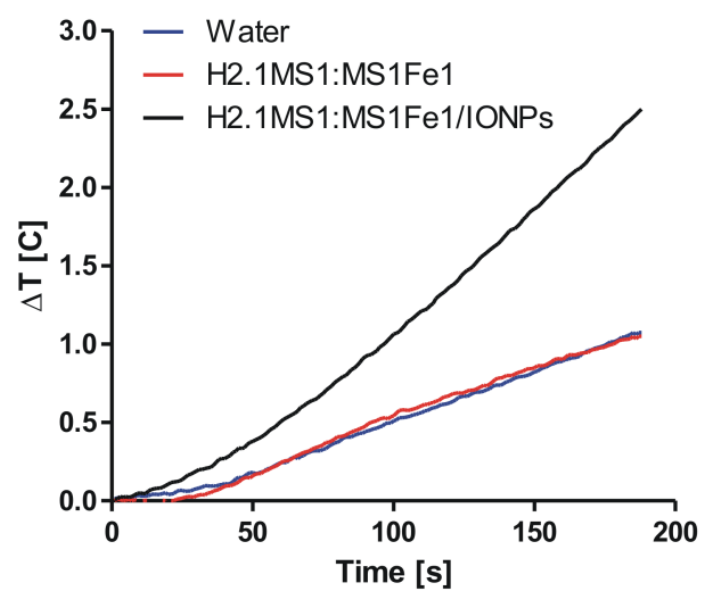

Fig. 8. Temperature measurement upon alternating magnetic field treatment of silk spheres. Spheres were prepared using an initial silk concentration of $2 \mathrm{mg} / \mathrm{ml}$ (with or without IONPs) and $2 \mathrm{M}$ potassium phosphate buffer. The analysis was performed over 180 seconds under an electric current of $300 \mathrm{~A}$ that fed the induction coil to achieve magnetic field of $H=16.2 \mathrm{kA} / \mathrm{m}$. The graph represents the mean of three measurements.

\subsection{Hyperthermia effect of composite blended spheres}

Her2-positive SKBR3 cells were treated with blended and composite blended spheres, and then, the magnetic field was applied. To investigate the effect of hyperthermia induced by magnetically treated spheres, cells were analyzed for apoptosis/necrosis. The results demonstrated that the experimental procedure caused a decrease in the viability of the cells, including the control cells that were not treated with particles (Fig. 9A). H2.1MS1:MS1Fe1/IONP spheres caused significant changes in the vitality of cells compared with H2.1MS1:MS1Fe1 particles, which resulted in an approximately 2.7 times higher percentage of cells being in the late phase of apoptosis (Fig. 9B, C). Moreover, we observed that the percentage of necrotic cells was approximately 6.4 times higher in cells treated with IONP-containing spheres than in nontreated cancer cells, which was significant (Fig. 9). 


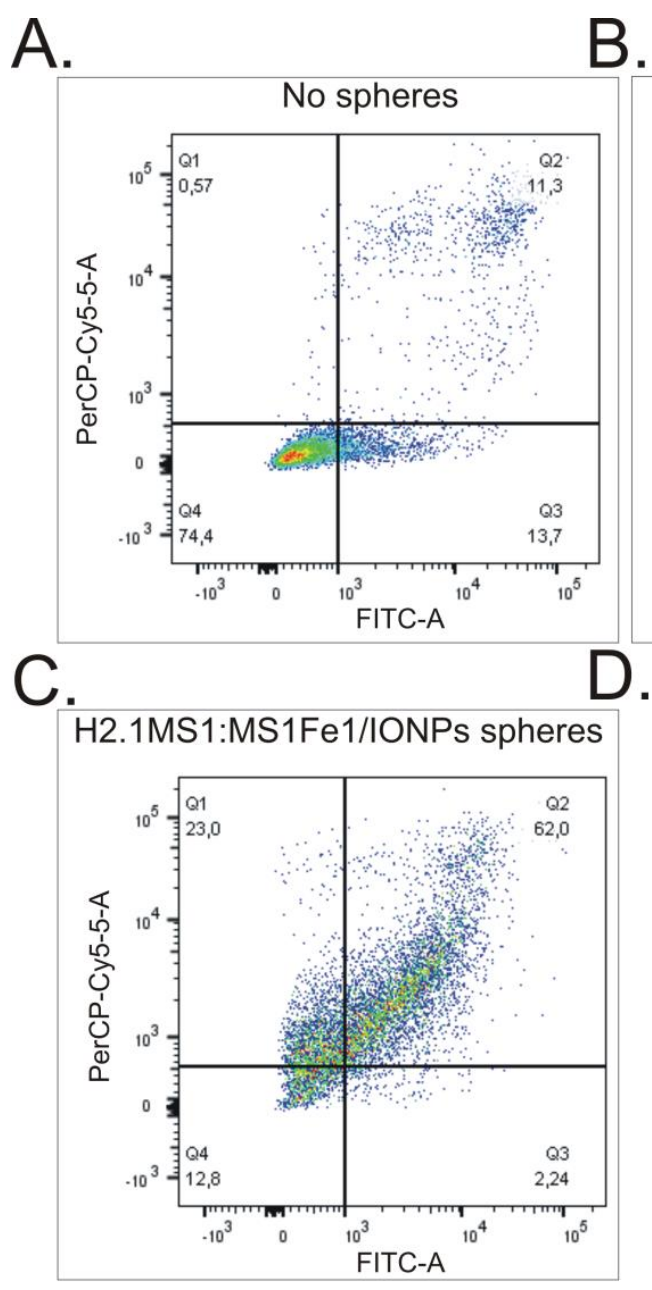

B.
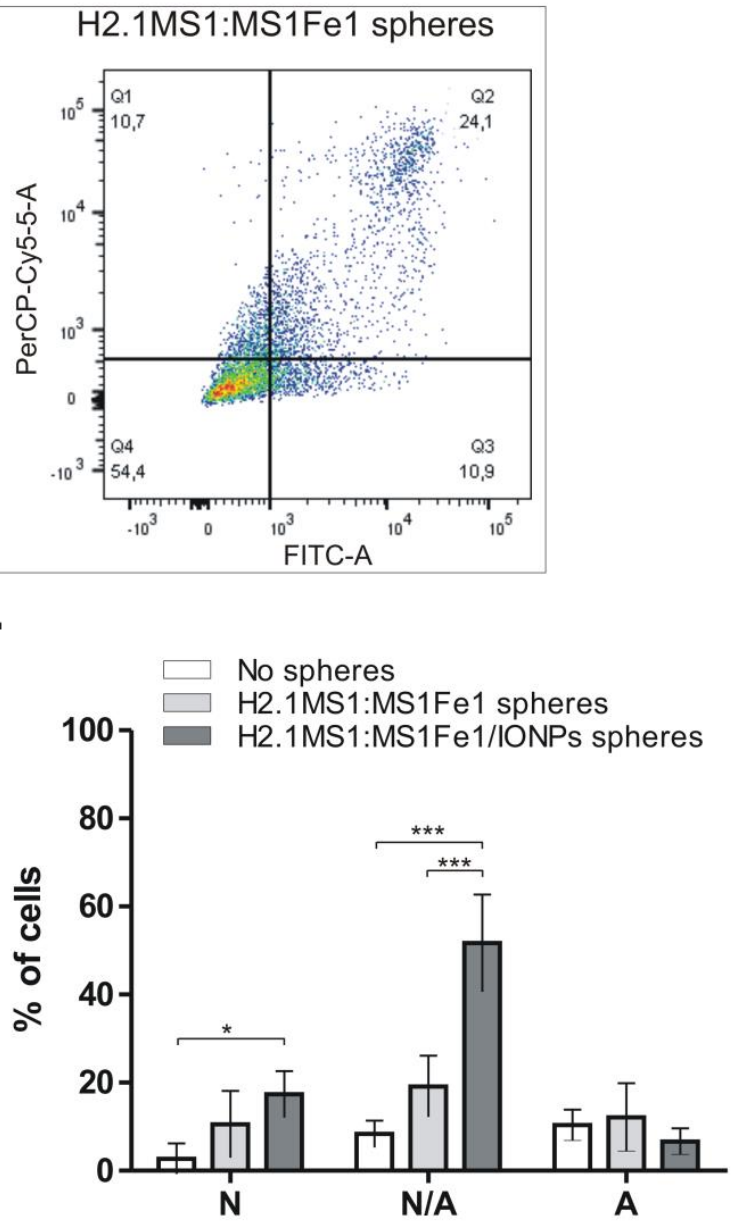

Fig. 9. Analysis of apoptosis and necrosis of SKBR3 cells treated with magnetically induced spheres. Representative graphs of the flow cytometry analysis of (A) cells not treated with spheres, (B) cells treated with H2.1MS1:MS1Fe1 spheres, and (C) cells treated with H2.1MS1:MS1Fe1/IONP particles. Quadrant designation: Q1 = necrosis, Q2 = late apoptosis, Q3 = apoptosis. (D) The diagram represents the means and standard deviations of three independent experiments of Annexin V/PI-stained hyperthermia-treated cells $(\mathrm{N}$, necrosis; N/A, late apoptosis; A, apoptosis). * indicates statistical significance with $\mathrm{p}<0.05$; *** indicates statistical significance with $\mathrm{p}<0.001$

\section{Discussion}


Due to the enhanced permeability and retention (EPR) effect, magnetic nanoparticles with sizes varying between 10 and $200 \mathrm{~nm}$ could be preferably accumulated in tumor tissue [53]. On the other hand, circulating IONPs in the bloodstream are susceptible to opsonization, which may result in their restricted accumulation at the tumor site [54]. The functionalization of magnetic nanoparticles by the addition of targeting domains may help overcome this phenomenon. Li et al. demonstrated that conjugation of an anti-Her2 antibody to $\mathrm{Fe}_{3} \mathrm{O}_{4}$ nanoparticles resulted in a threefold increase in IONP uptake into MBT-2 (Her2overexpressing) cells compared with conjugation with nonspecific mAb [55]. The uptake of these IONPs by healthy control cells was significantly lower, indicating an effective targeting strategy. Moreover, magnetic drug targeting (MDT) can be applied to improve the selective administration of nanoparticles into the cancer environment. The intravascular injected drugloaded IONPs were guided by the external magnetic field to the tumor site [56]. Tian et al. indicated that intravenously injected doxorubicin-loaded magnetic silk fibroin nanoparticles were guided specifically to MCF-7 breast cancer cells via magnetic forces [57].

Several studies have investigated the simultaneous application of both delivery methods, i.e., magnetic field and targeting peptides. Sang and coworkers produced polymeric micelles that contained iron oxide nanoparticles and were functionalized with hyaluronic acid (which can target the CD44 receptor). After application of the magnetic field, these particles exhibited significantly stronger affinity and intercellular penetration of 4T1 cancer cells than the control [58]. Effective targeting was also observed during in vivo imaging of tumorbearing mice after intravenous injection of these magnetic nanoparticles and exposure to a magnetic field [58]. Angelopoulou et al. examined magnetic nanoparticles functionalized with folic acid (FA). FA binds to a folate receptor $(\mathrm{FR} \alpha)$ that is overexpressed on certain types of cancer cells. The application of these functionalized nanoparticles and a magnetic field 
resulted in highly accelerated uptake into FRa-overexpressing MDA-MB 231 breast cancer cells in comparison with control MCF-7 cells [59].

We previously investigated the possibility of obtaining biocompatible magnetic particles made of a composite material containing bioengineered spider silk protein and iron oxide nanoparticles [44]. Among the tested silks (MS1, MS2, and EMS2), the EMS2 variant exhibited the highest affinity for IONPs [44]. However, the level of IONPs bound to EMS2 spheres was relatively low. Unfortunately, the bioengineered silks based on the MaSp2 spidroin of the $N$. clavipes spider exhibited poor binding to cells [45], and the EMS2 silk originated from this spidroin [37]. On the other hand, in another study, we indicated the specific and selective binding of H2.1MS1 spheres to Her2-positive cancer cells [38]. The H2.1MS1 silk was functionalized with the H2.1 peptide, which determined the specificity of the silk spheres. Thus, to improve the magnetic properties and simultaneously the cell binding properties of silk spheres, we applied a new approach.

In this study, new variants of functionalized silk proteins were obtained. It was shown that the Fe1 (KSLSRHDHIHHH) and Fe2 (SVSVGMKPSPRP) peptides exhibited affinity for different metal compounds $[49,50]$. Thus, we produced three variants of the bioengineered silks (MS1Fe1, MS1Fe2, MS1Fe1Fe2) that contained the functional peptide Fe1 or/and Fe2. First, we examined which new variant of silk bound the highest levels of the positively or negatively charged IONPs. Next, the selected iron-binding silk variant was blended with H2.1MS1 silk to obtain composite blended spheres that could enable the delivery of IONPs to Her2-positive cancer cells. This could be beneficial for tumor diagnostic or/and therapeutic purposes (for drug delivery and/or to induce hyperthermia).

The spheres were produced using the salting out method as indicated previously [ 30 , $33,37,38,60,61]$. We observed that addition of the $\mathrm{Fe} 1$ and $\mathrm{Fe} 2$ peptides increased the IONP 
content in the examined particles compared with the control sMS1 spheres. The combination of silk proteins with IONPs with positive charge resulted in the generation of spheres that were characterized by a sticky morphology. Moreover, the amount of negatively charged IONPs on the sphere surface was higher than that of positively charged IONPs. All silk variants exhibited a positive charge at $\mathrm{pH} 8$ ( $\mathrm{pI}$ approximately 10); thus, electrostatic interactions may explain this phenomenon. We also demonstrated the difference in the affinity of IONPs to silk particles according to the functional peptide variant. The Fel peptide was more effective in binding IONPs than the Fe2 peptide. This may be the result of the amino acid composition of this peptide. Studies by Lu et al. and Barber-Zucker et al. showed that $\mathrm{Fe}^{3+}$ ions preferentially bind to amino acid residues such as histidine (H) and aspartic acid (D) $[62,63]$. The highest number of histidine and aspartic acid residues (10 and 2, respectively) in the MS1Fe1 silk protein sequence could have led to the increased IONP content in the analyzed spheres compared with the MS1Fe2 and MS1Fe1Fe2 variants.

In the next step of our study, we added H2.1MS1 silk to the MS1Fe1 protein and then investigated composite spheres made of such silk blends and negatively charged IONPs. The idea of blending various types of silk is not novel. Nileback et al. demonstrated the formation of various morphological structures made of recombinant spider silk combined with silk fibroin [64]. Studies by Florczak et al. showed the possibility of blending functionalized spider silk proteins and the production of spheres from an obtained silk blend [45]. Materials produced from mixtures of two different bioengineered silks containing various affinity domains displayed combined binding properties [65]. To enable the binding of particles to Her2-positive cancer cells, we produced a H2.1MS1:MS1Fe1 silk blend.

First, the silk proteins were blended at different ratios and then used to form ironcontaining composite spheres, and their specific cell binding was investigated. Two factors could interfere with the binding process: i) the number of $\mathrm{H} 2.1$ peptides might not be 
sufficient for allowing specific cell recognition and binding, and/or ii) the IONPs could mask/impede the external exposure of $\mathrm{H} 2.1$ peptides. Our results demonstrated the specific cell binding for all sphere variants containing the H2.1 peptide, which decreased with decreasing amounts of this peptide in the silk blend. The blended spheres composed of functionalized silks, H2.1MS1:MS1Fe1, at a weight ratio of $8: 2$ maintained the binding efficiency to target cells at the same level as that of H2.1MS1 particles. Interestingly, the study by Florczak et al. indicated similar findings related to the mixing ratio of various silks and their biding potential [45]. Moreover, these particles (H2.1MS1:MS1Fe1 blended at a ratio of $8: 2$ ) contained 1.5 times more IONPs than H2.1MS1 spheres and 3.4 times more IONPs than EMS2/IONP spheres as previously reported by our group [44]. Furthermore, these selected composite blended spheres also retained their potential to load doxorubicin. The highest drug-loading capacity was indicated for the MS1 spheres. As we indicated previously, MS1 spheres despite the positive charge efficiently bound the positively charged Dox probably due to hydrophobic interactions [33]. From the one side, the pores inside the MS1 particles could allow penetrating the drug inside the sphere's core. However, on the other hand, the increase of the positive surface charge of the MS1 spheres after Dox loading indicated the presence of doxorubicin on the spheres surface [33]. In this study, the addition of the functional peptides decreased the doxorubicin-loading potential of the silk spheres. However, these functionalizations, in addition to specific targeting, also enabled the efficient binding of IONPs, which in turn allowed restoration of the level of drug loading. The doxorubicin loading in composite blended spheres was at the same level as that in MS1 particles. The iron oxide nanoparticles on the sphere's surface might provide an additional binding surface for doxorubicin. The negatively charged IONPs could trigger binding of the positively charged Dox. Additionally, the thermal analysis of H21MS1:MS1Fe1/IONPs/Dox particles was performed, which indicated two major weight loss phases. The initial weight 
loss of Dox-loaded spheres, observed till $100{ }^{\circ} \mathrm{C}$, could be attributed to the evaporation of water from the sample, which was mentioned in previous studies for silk based structures [6668]. The main weight loss of H21MS1:MS1Fe1/IONPs/Dox particles took place in the temperature range of $250-750{ }^{\circ} \mathrm{C}$ which may be associated with the decomposition of the side chain groups of the amino acid residues and the breakdown of peptide bonds [69].

The release kinetics of doxorubicin exhibited $\mathrm{pH}$-dependent profiles for both types of spheres with slow release at neutral $\mathrm{pH}(\mathrm{pH} 7.4)$ and fast release in acidic environments $(\mathrm{pH}$ 4.5). These results are in agreement with those of previous studies [33, 37, 38, 42, 44]. Sanson et al. showed that acidic $\mathrm{pH}$ stimulates the transition of doxorubicin to its hydrophilic form, which enhances its rate of release from delivery vehicles [70]. The H2.1MS1:MS1Fe1/IONP spheres released less drug in buffer at $\mathrm{pH} 7.4$ than the H2.1MS1:MS1Fe1 particles. The decreased release of doxorubicin from composite spheres at neutral $\mathrm{pH}$ may be beneficial for the potential administration of these carriers into the bloodstream. On the other hand, the addition of IONPs to H2.1MS1:MS1Fe spheres was not as beneficial in terms of doxorubicin release as observed for EMS2/IONP spheres [44]. In the case of EMS2/IONPs/Dox, the iron oxide particles inhibited the burst release of the drug at a $\mathrm{pH}$ of 7.4 , in contrast to the composite blended spheres presented in this study. The burst release of Dox from H2.1MS1:MS1Fe1/IONP particles also may indicate the presence of the drug on the surface of the spheres. The surface localization of the drug would make it more susceptible to being washed out during the release examination. It needs further study. This finding highlights that the loading and release of the drug are multifactor processes and depend on the properties of the silk type as well as IONPs.

Moreover, the H2.1MS1:MS1Fe1/IONPs/Dox spheres were not effective in cell killing. Although the composite blended spheres exhibited higher Dox loading and Dox release at a $\mathrm{pH}$ of 4.5 than the blended silk particles, their cytotoxic effect was not 
significantly improved. These spheres had a significantly stronger toxic effect on cells than the blended spheres only at the highest concentration. This suggests that H2.1MS1:MS1Fe1/IONPs could bind to Her2-positive cells but could not be internalized. Previously, we indicated that H2.1MS1 and H2.1MS1:H2.1MS2 spheres not only bound to the surface of targeted cells but were also internalized through both the clathrin- and caveoladependent pathways of endocytosis [71]. These particles were trafficked to lysosomes, where their degradation occurred [71]. Furthermore, the released Dox was trafficked to the nucleus, causing cell death $[38,45]$. The particles analyzed in the previous study were more effective than those in this study, as a much lower concentration of silk spheres was needed to cause cytotoxic effects $[38,45]$ compared with the concentration of particles presented in this work. Moreover, the Dox-loaded blended silk spheres (without IONPs) did not effectively exert the cytotoxic effect. Since both blended spheres (with and without IONPs) contained MS1Fe1 silk, functionalization with the Fel peptide could impede the cell internalization of these spheres. However, this aspect needs to be further studied. It is also worth mentioning that the rate of doxorubicin release from composite magnetic nanoparticles at acidic $\mathrm{pH}$ could be increased by exposure to the magnetic field [59]. These results suggest that we may achieve even higher release of Dox from H2.1MS1:MS1Fe1/IONP spheres during the magnetic treatment of cancer.

The concept of hyperthermia involves the induction of cancer cell apoptosis by local high-temperature generation. One of such approaches is the photo-thermal therapy (PTT) that utilizes the photo-absorbing agents such as carbon nanotubes, graphene oxide, gold nanoparticles to produce heat in the tumor lesion to locally destroy cancer cells [73-75]. On the other hand, the IONPs can be used for heat generation [76]. The superparamagnetic nanoparticles placed in an alternating magnetic field undergo Brownian relaxation (rotation of the nanoparticles) and the Néel relaxation (reorientation of the magnetic moment inside the 
magnetic core against an anisotropy energy barrier), which can result in noticeable temperature increase [77]. Zhao et al. demonstrated the death of human head and neck cancer cells in a mouse model after IONP-mediated magnetic hyperthermia [78]. Moreover, the overheating of cells can stimulate the anti-cancer immune response. Baker et al. showed an increased response involving $\mathrm{T}$ lymphocytes in murine melanoma tissue following hyperthermia treatment [79]. In our studies, a substantial increase in temperature was observed for the composite sphere sample under the influence of an alternating magnetic field. This phenomenon confirmed the superparamagnetic properties of H2.1MS1:MS1Fe1/IONP particles and their potential application in hyperthermia treatment.

Moreover, the analysis demonstrated a significant increase in the percentage of late apoptotic and necrotic cell populations in H2.1MS1:MS1Fe1/IONP-treated cells in comparison with the controls. These results indicated successful local heat generation caused by composite blended spheres and an applied magnetic field, which finally led to cancer cell disruption and, eventually, cell death. Other studies described the cell apoptosis induced via magnetic iron oxide nanoparticle hyperthermia [80-83]; however, no results regarding spider silk/IONP composite material spheres have been published thus far. In future work, we will examine our system in an in vivo model. Chen et al. investigated the targeting of breast cancer (4T1)-bearing mice with dual-ligand iron oxide agents for hyperthermia treatment [84]. The studies showed a preferential increase in temperature in tumor tissue and a significant reduction in tumor volume after magnetic hyperthermia therapy. The promising effects of IONPs in thermal treatment evaluation were also reported in the case of a glioblastoma animal model. After the administration of $\mathrm{Fe}_{3} \mathrm{O}_{4}$-aminosilane-coated nanoparticles and exposure to an alternating magnetic field, an almost $33 \%$ decrease in tumor mass relative to the control was observed [85]. Anticancer therapy based on magnetite nanoparticles combining chemotherapy and targeted hyperthermia was described by Li et al. [55]. The application of IONPs 
functionalized with anti-Her2 and loaded with 5-fluorouracil resulted in significant tumor regression in both early- and late-stage tumors under hyperthermia generation. Taking into account these reports and the results of our studies, we have developed a system that may have great potential in targeted hyperthermia-mediated cancer chemotherapy.

\section{Conclusions}

The composite blended spheres H2.1MS1:MS1Fe1/IONP characterized in our study appear to be a versatile tool in medical applications. The introduction of superparamagnetic iron oxide nanoparticles and doxorubicin in the biocompatible silk provided the possibility for both diagnostic and therapeutic applications of the system. Via the functionalization of silk with H2.1 peptide, we gained the ability to perform the targeted delivery of drug carriers to Her2-overexpressing cancer cells. On the other hand, via the addition of the Fe1 peptide, the increased IONP loading into silk spheres was achieved. In addition to chemotherapeutic treatment (delivering Dox), hyperthermia-induced apoptosis of cancer cells by the application of H2.1MS1:MS1Fe1/IONP spheres may cause cell death and stimulate the immunological response through the presentation of tumor-specific antigens.

\section{Conflicts of interest}

The authors declare no conflict of interests.

\section{Acknowledgments}

We would like to thank NanoBioMedical Centre (NBMC) at Adam Mickiewicz University in Poznan, Poland, for the availability of using the microscope (JEOL JSM7001F). Thank you David Kaplan (Tufts University, Medford, Massachusetts, USA) for plasmids pET30a-MS16xFe1 and pET30a-MS16xFe2. The project was partially supported by a grant from The National Science Centre, Poland (2014/15/B/NZ7/00903). 


\section{References}

[1] R.L. Siegel, K.D. Miller, A. Jemal, Cancer statistics, 2018, CA Cancer J Clin, 68 (2018) 730 .

[2] Y. Octavia, C.G. Tocchetti, K.L. Gabrielson, S. Janssens, H.J. Crijns, A.L. Moens, Doxorubicin-induced cardiomyopathy: from molecular mechanisms to therapeutic strategies, J Mol Cell Cardiol, 52 (2012) 1213-1225.

[3] T. Simunek, M. Sterba, O. Popelova, M. Adamcova, R. Hrdina, V. Gersl, Anthracyclineinduced cardiotoxicity: overview of studies examining the roles of oxidative stress and free cellular iron, Pharmacol Rep, 61 (2009) 154-171.

[4] M. Sterba, O. Popelova, A. Vavrova, E. Jirkovsky, P. Kovarikova, V. Gersl, T. Simunek, Oxidative stress, redox signaling, and metal chelation in anthracycline cardiotoxicity and pharmacological cardioprotection, Antioxid Redox Signal, 18 (2013) 899-929.

[5] B. Kalyanaraman, Teaching the basics of the mechanism of doxorubicin-induced cardiotoxicity: Have we been barking up the wrong tree?, Redox Biol, 29 (2020) 101394.

[6] V.S. Madamsetty, A. Mukherjee, S. Mukherjee, Recent Trends of the Bio-Inspired Nanoparticles in Cancer Theranostics, Front Pharmacol, 10 (2019) 1264.

[7] R. Singh, Nanotechnology based therapeutic application in cancer diagnosis and therapy, 3 Biotech, 9 (2019) 415.

[8] Y.P. Ho, K.W. Leong, Quantum dot-based theranostics, Nanoscale, 2 (2010) 60-68.

[9] M.S. Muthu, D.T. Leong, L. Mei, S.S. Feng, Nanotheranostics - application and further development of nanomedicine strategies for advanced theranostics, Theranostics, 4 (2014) 660-677.

[10] R.S. Kalash, V.K. Lakshmanan, C.-S. Cho, I.-K. Park, 4.4 - Theranostics, in: M. Ebara (Ed.) Biomaterials Nanoarchitectonics, William Andrew Publishing, 2016, pp. 197-215.

[11] L. Zhu, Z. Zhou, H. Mao, L. Yang, Magnetic nanoparticles for precision oncology: theranostic magnetic iron oxide nanoparticles for image-guided and targeted cancer therapy, Nanomedicine (Lond), 12 (2017) 73-87.

[12] E. Attari, H. Nosrati, H. Danafar, H. Kheiri Manjili, Methotrexate anticancer drug delivery to breast cancer cell lines by iron oxide magnetic based nanocarrier, J Biomed Mater Res A, 107 (2019) 2492-2500.

[13] C.G. Hiremath, G.B. Heggnnavar, M.Y. Kariduraganavar, M.B. Hiremath, Co-delivery of paclitaxel and curcumin to foliate positive cancer cells using Pluronic-coated iron oxide nanoparticles, Prog Biomater, 8 (2019) 155-168. 
[14] A. Morovati, S. Ahmadian, H. Jafary, Cytotoxic effects and apoptosis induction of cisplatin-loaded iron oxide nanoparticles modified with chitosan in human breast cancer cells, Mol Biol Rep, 46 (2019) 5033-5039.

[15] K. El-Boubbou, Magnetic iron oxide nanoparticles as drug carriers: preparation, conjugation and delivery, Nanomedicine (Lond), 13 (2018) 929-952.

[16] Z. Fang, X. Li, Z. Xu, F. Du, W. Wang, R. Shi, D. Gao, Hyaluronic acid-modified mesoporous silica-coated superparamagnetic Fe3O4 nanoparticles for targeted drug delivery, Int J Nanomedicine, 14 (2019) 5785-5797.

[17] K. Kaczmarek, T. Hornowski, I. Antal, M. Rajnak, M. Timko, A. Józefczak, Sonomagnetic heating in tumor phantom, Journal of Magnetism and Magnetic Materials, 500 (2020) 166396.

[18] A. Ito, H. Honda, T. Kobayashi, Cancer immunotherapy based on intracellular hyperthermia using magnetite nanoparticles: a novel concept of "heat-controlled necrosis" with heat shock protein expression, Cancer Immunol Immunother, 55 (2006) 320-328.

[19] M.K. Lima-Tenorio, E.A. Pineda, N.M. Ahmad, H. Fessi, A. Elaissari, Magnetic nanoparticles: In vivo cancer diagnosis and therapy, Int J Pharm, 493 (2015) 313-327.

[20] S. Talluri, R.R. Malla, Superparamagnetic Iron Oxide Nanoparticles (SPIONs) for Diagnosis and Treatment of Breast, Ovarian and Cervical Cancers, Curr Drug Metab, (2019). [21] M. Kręcisz, J.D. Rybka, A.J. Strugała, B. Skalski, M. Figlerowicz, M. Kozak, M. Giersig, Interactions between magnetic nanoparticles and model lipid bilayers-Fourier transformed infrared spectroscopy (FTIR) studies of the molecular basis of nanotoxicity, Journal of Applied Physics, 120 (2016) 124701.

[22] L. Zecca, M.B. Youdim, P. Riederer, J.R. Connor, R.R. Crichton, Iron, brain ageing and neurodegenerative disorders, Nat Rev Neurosci, 5 (2004) 863-873.

[23] T.R. Pisanic, 2nd, J.D. Blackwell, V.I. Shubayev, R.R. Finones, S. Jin, Nanotoxicity of iron oxide nanoparticle internalization in growing neurons, Biomaterials, 28 (2007) 25722581.

[24] K. Spiess, A. Lammel, T. Scheibel, Recombinant spider silk proteins for applications in biomaterials, Macromol Biosci, 10 (2010) 998-1007.

[25] K. Schacht, T. Scheibel, Processing of recombinant spider silk proteins into tailor-made materials for biomaterials applications, Curr Opin Biotechnol, 29 (2014) 62-69.

[26] A. Rising, M. Widhe, J. Johansson, M. Hedhammar, Spider silk proteins: recent advances in recombinant production, structure-function relationships and biomedical applications, Cell Mol Life Sci, 68 (2011) 169-184. 
[27] C. Holland, K. Numata, J. Rnjak-Kovacina, F.P. Seib, The Biomedical Use of Silk: Past, Present, Future, Adv Healthc Mater, 8 (2019) e1800465.

[28] M.G. Montalban, J.M. Coburn, A.A. Lozano-Perez, J.L. Cenis, G. Villora, D.L. Kaplan, Production of Curcumin-Loaded Silk Fibroin Nanoparticles for Cancer Therapy, Nanomaterials (Basel), 8 (2018).

[29] T. Wongpinyochit, B.F. Johnston, F.P. Seib, Manufacture and Drug Delivery Applications of Silk Nanoparticles, J Vis Exp, (2016).

[30] A. Lammel, M. Schwab, M. Hofer, G. Winter, T. Scheibel, Recombinant spider silk particles as drug delivery vehicles, Biomaterials, 32 (2011) 2233-2240.

[31] M. Hofer, G. Winter, J. Myschik, Recombinant spider silk particles for controlled delivery of protein drugs, Biomaterials, 33 (2012) 1554-1562.

[32] M.B. Schierling, E. Doblhofer, T. Scheibel, Cellular uptake of drug loaded spider silk particles, Biomater Sci, 4 (2016) 1515-1523.

[33] K. Jastrzebska, A. Florczak, K. Kucharczyk, Y. Lin, Q. Wang, A. Mackiewicz, D.L. Kaplan, H. Dams-Kozlowska, Delivery of chemotherapeutics using spheres made of bioengineered spider silks derived from MaSp1 and MaSp2 proteins, Nanomedicine (Lond), 13 (2018) 439-454.

[34] K. Numata, A.J. Mieszawska-Czajkowska, L.A. Kvenvold, D.L. Kaplan, Silk-based nanocomplexes with tumor-homing peptides for tumor-specific gene delivery, Macromol Biosci, 12 (2012) 75-82.

[35] T. Deptuch, H. Dams-Kozlowska, Silk Materials Functionalized via Genetic Engineering for Biomedical Applications, Materials (Basel), 10 (2017).

[36] E. Doblhofer, T. Scheibel, Engineering of recombinant spider silk proteins allows defined uptake and release of substances, J Pharm Sci, 104 (2015) 988-994.

[37] K. Kucharczyk, M. Weiss, K. Jastrzebska, M. Luczak, A. Ptak, M. Kozak, A. Mackiewicz, H. Dams-Kozlowska, Bioengineering the spider silk sequence to modify its affinity for drugs, Int J Nanomedicine, 13 (2018) 4247-4261.

[38] A. Florczak, A. Mackiewicz, H. Dams-Kozlowska, Functionalized spider silk spheres as drug carriers for targeted cancer therapy, Biomacromolecules, 15 (2014) 2971-2981.

[39] M.B. Elsner, H.M. Herold, S. Muller-Herrmann, H. Bargel, T. Scheibel, Enhanced cellular uptake of engineered spider silk particles, Biomater Sci, 3 (2015) 543-551.

[40] A.K. Kozlowska, A. Florczak, M. Smialek, E. Dondajewska, A. Mackiewicz, M. Kortylewski, H. Dams-Kozlowska, Functionalized bioengineered spider silk spheres improve 
nuclease resistance and activity of oligonucleotide therapeutics providing a strategy for cancer treatment, Acta Biomater, 59 (2017) 221-233.

[41] K. Numata, M.R. Reagan, R.H. Goldstein, M. Rosenblatt, D.L. Kaplan, Spider silk-based gene carriers for tumor cell-specific delivery, Bioconjug Chem, 22 (2011) 1605-1610.

[42] H. Zhang, X. Ma, C. Cao, M. Wang, Y. Zhu, Multifunctional iron oxide/silk-fibroin (Fe3O4-SF) composite microspheres for the delivery of cancer therapeutics, RSC Advances, 4 (2014) 41572-41577.

[43] A.Z. Chen, L.Q. Chen, S.B. Wang, Y.Q. Wang, J.Z. Zha, Study of magnetic silk fibroin nanoparticles for massage-like transdermal drug delivery, Int J Nanomedicine, 10 (2015) 4639-4651.

[44] K. Kucharczyk, J.D. Rybka, M. Hilgendorff, M. Krupinski, M. Slachcinski, A. Mackiewicz, M. Giersig, H. Dams-Kozlowska, Composite spheres made of bioengineered spider silk and iron oxide nanoparticles for theranostics applications, PLoS One, 14 (2019) e0219790.

[45] A. Florczak, K. Jastrzebska, A. Mackiewicz, H. Dams-Kozlowska, Blending two bioengineered spider silks to develop cancer targeting spheres, Journal of Materials Chemistry B, 5 (2017) 3000-3011.

[46] L.L. Canabady-Rochelle, D.J. Belton, O. Deschaume, H.A. Currie, D.L. Kaplan, C.C. Perry, Bioinspired silicification of silica-binding peptide-silk protein chimeras: comparison of chemically and genetically produced proteins, Biomacromolecules, 13 (2012) 683-690.

[47] E. Estephan, C. Larroque, F.J. Cuisinier, Z. Balint, C. Gergely, Tailoring GaN semiconductor surfaces with biomolecules, J Phys Chem B, 112 (2008) 8799-8805.

[48] M.D. Roy, S.K. Stanley, E.J. Amis, M.L. Becker, Identification of a Highly Specific Hydroxyapatite-binding Peptide using Phage Display, Advanced Materials, 20 (2008) 18301836.

[49] B.D. Reiss, C. Mao, D.J. Solis, K.S. Ryan, T. Thomson, A.M. Belcher, Biological Routes to Metal Alloy Ferromagnetic Nanostructures, Nano Letters, 4 (2004) 1127-1132.

[50] E. Estephan, J. Dao, M.B. Saab, I. Panayotov, M. Martin, C. Larroque, C. Gergely, F.J. Cuisinier, B. Levallois, SVSVGMKPSPRP: a broad range adhesion peptide, Biomed Tech (Berl), 57 (2012) 481-489.

[51] C.J. Witton, J.R. Reeves, J.J. Going, T.G. Cooke, J.M. Bartlett, Expression of the HER14 family of receptor tyrosine kinases in breast cancer, J Pathol, 200 (2003) 290-297. 
[52] A. Florczak, K. Jastrzebska, W. Bialas, A. Mackiewicz, H. Dams-Kozlowska, Optimization of spider silk sphere formation processing conditions to obtain carriers with controlled characteristics, J Biomed Mater Res A, 106 (2018) 3211-3221.

[53] Z. Ferjaoui, E. Jamal Al Dine, A. Kulmukhamedova, L. Bezdetnaya, C. Soon Chang, R. Schneider, F. Mutelet, D. Mertz, S. Begin-Colin, F. Quiles, E. Gaffet, H. Alem, DoxorubicinLoaded Thermoresponsive Superparamagnetic Nanocarriers for Controlled Drug Delivery and Magnetic Hyperthermia Applications, ACS Appl Mater Interfaces, 11 (2019) 30610-30620.

[54] C.C. Berry, A.S.G. Curtis, Functionalisation of magnetic nanoparticles for applications in biomedicine, Journal of Physics D: Applied Physics, 36 (2003) R198-R206.

[55] T.J. Li, C.C. Huang, P.W. Ruan, K.Y. Chuang, K.J. Huang, D.B. Shieh, C.S. Yeh, In vivo anti-cancer efficacy of magnetite nanocrystal--based system using locoregional hyperthermia combined with 5-fluorouracil chemotherapy, Biomaterials, 34 (2013) 7873 7883.

[56] S. Lyer, R. Singh, R. Tietze, C. Alexiou, Magnetic nanoparticles for magnetic drug targeting, Biomed Tech (Berl), 60 (2015) 465-475.

[57] Y. Tian, X. Jiang, X. Chen, Z. Shao, W. Yang, Doxorubicin-loaded magnetic silk fibroin nanoparticles for targeted therapy of multidrug-resistant cancer, Adv Mater, 26 (2014) 73937398.

[58] M. Sang, L. Han, R. Luo, W. Qu, F. Zheng, K. Zhang, F. Liu, J. Xue, W. Liu, F. Feng, CD44 targeted redox-triggered self-assembly with magnetic enhanced EPR effects for effective amplification of gambogic acid to treat triple-negative breast cancer, Biomaterials Science, 8 (2020) 212-223.

[59] A. Angelopoulou, A. Kolokithas-Ntoukas, C. Fytas, K. Avgoustakis, Folic AcidFunctionalized, Condensed Magnetic Nanoparticles for Targeted Delivery of Doxorubicin to Tumor Cancer Cells Overexpressing the Folate Receptor, ACS Omega, 4 (2019) 2221422227.

[60] U.K. Slotta, S. Rammensee, S. Gorb, T. Scheibel, An engineered spider silk protein forms microspheres, Angew Chem Int Ed Engl, 47 (2008) 4592-4594.

[61] A.S. Lammel, X. Hu, S.H. Park, D.L. Kaplan, T.R. Scheibel, Controlling silk fibroin particle features for drug delivery, Biomaterials, 31 (2010) 4583-4591.

[62] C.H. Lu, Y.F. Lin, J.J. Lin, C.S. Yu, Prediction of metal ion-binding sites in proteins using the fragment transformation method, PLoS One, 7 (2012) e39252. 
[63] S. Barber-Zucker, B. Shaanan, R. Zarivach, Transition metal binding selectivity in proteins and its correlation with the phylogenomic classification of the cation diffusion facilitator protein family, Sci Rep, 7 (2017) 16381.

[64] L. Nileback, D. Chouhan, R. Jansson, M. Widhe, B.B. Mandal, M. Hedhammar, SilkSilk Interactions between Silkworm Fibroin and Recombinant Spider Silk Fusion Proteins Enable the Construction of Bioactive Materials, ACS Appl Mater Interfaces, 9 (2017) 3163431644.

[65] R. Jansson, N. Thatikonda, D. Lindberg, A. Rising, J. Johansson, P.A. Nygren, M. Hedhammar, Recombinant spider silk genetically functionalized with affinity domains, Biomacromolecules, 15 (2014) 1696-1706.

[66] Y. Baimark, Morphology and thermal stability of silk fibroin/starch blended microparticles, eXPRESS Polymer Letters, 4 (2010) 781-789.

[67] G.R. Shetty, B.L. Rao, S. Asha, Y. Wang, Y. Sangappa, Preparation and characterization of silk fibroin/hydroxypropyl methyl cellulose (HPMC) blend films, Fibers and Polymers, 16 (2015) 1734-1741.

[68] N. Parushuram, R. Ranjana, B. Narayana, M. Mahendra, Y. Sangappa, Facile fabrication of silk fibroin microparticles: their characterization and potential adsorption study, Journal of Dispersion Science and Technology, (2020) 1-19.

[69] S.M. Lee, D. Cho, W.H. Park, S.G. Lee, S.O. Han, L.T. Drzal, Novel silk/poly(butylene succinate) biocomposites: the effect of short fibre content on their mechanical and thermal properties, Composites Science and Technology, 65 (2005) 647-657.

[70] C. Sanson, C. Schatz, J.F. Le Meins, A. Soum, J. Thevenot, E. Garanger, S. Lecommandoux, A simple method to achieve high doxorubicin loading in biodegradable polymersomes, J Control Release, 147 (2010) 428-435.

[71] A. Florczak, A. Mackiewicz, H. Dams-Kozlowska, Cellular uptake, intracellular distribution and degradation of Her2-targeting silk nanospheres, Int J Nanomedicine, 14 (2019) 6855-6865.

[72] I. Hilger, In vivo applications of magnetic nanoparticle hyperthermia, Int $\mathbf{J}$ Hyperthermia, 29 (2013) 828-834.

[73] Y. Hashida, H. Tanaka, S. Zhou, S. Kawakami, F. Yamashita, T. Murakami, T. Umeyama, H. Imahori, M. Hashida, Photothermal ablation of tumor cells using a singlewalled carbon nanotube-peptide composite, J Control Release, 173 (2014) 59-66. 
[74] R. Mendes, P. Pedrosa, J.C. Lima, A.R. Fernandes, P.V. Baptista, Photothermal enhancement of chemotherapy in breast cancer by visible irradiation of Gold Nanoparticles, Sci Rep, 7 (2017) 10872.

[75] S.B. Maddinedi, J. Sonamuthu, K.Y.S. Suzu, G. Han, Y. Cai, J. Gao, Q. Ni, J. Yao, Silk sericin induced fabrication of reduced graphene oxide and its in-vitro cytotoxicity, photothermal evaluation, J Photochem Photobiol B, 186 (2018) 189-196.

[76] J. Jose, R. Kumar, S. Harilal, G.E. Mathew, D.G.T. Parambi, A. Prabhu, M.S. Uddin, L. Aleya, H. Kim, B. Mathew, Magnetic nanoparticles for hyperthermia in cancer treatment: an emerging tool, Environ Sci Pollut Res Int, 27 (2020) 19214-19225.

[77] M. Babincová, D. Leszczynska, P. Sourivong, P. Čičmanec, P. Babinec, Superparamagnetic gel as a novel material for electromagnetically induced hyperthermia, Journal of Magnetism and Magnetic Materials, 225 (2001) 109-112.

[78] Q. Zhao, L. Wang, R. Cheng, L. Mao, R.D. Arnold, E.W. Howerth, Z.G. Chen, S. Platt, Magnetic nanoparticle-based hyperthermia for head \& neck cancer in mouse models, Theranostics, 2 (2012) 113-121.

[79] I. Baker, S.N. Fiering, K.E. Griswold, P.J. Hoopes, K. Kekalo, C. Ndong, K. Paulsen, A.A. Petryk, B. Pogue, F. Shubitidze, J. Weaver, The Dartmouth Center for Cancer Nanotechnology Excellence: magnetic hyperthermia, Nanomedicine (London, England), 10 (2015) 1685-1692.

[80] A. Neshastehriz, Z. Khosravi, H. Ghaznavi, A. Shakeri-Zadeh, Gold-coated iron oxide nanoparticles trigger apoptosis in the process of thermo-radiotherapy of U87-MG human glioma cells, Radiat Environ Biophys, 57 (2018) 405-418.

[81] A. Ereath Beeran, F.B. Fernandez, P.R.H. Varma, Self-Controlled Hyperthermia \& MRI Contrast Enhancement via Iron Oxide Embedded Hydroxyapatite Superparamagnetic particles for Theranostic Application, ACS Biomaterials Science \& Engineering, 5 (2019) 106-113.

[82] Y. Oh, N. Lee, H.W. Kang, J. Oh, In vitro study on apoptotic cell death by effective magnetic hyperthermia with chitosan-coated $\mathrm{MnFe}(2) \mathrm{O}(4)$, Nanotechnology, 27 (2016) 115101.

[83] M. Sanhaji, J. Göring, P. Couleaud, A. Aires, A.L. Cortajarena, J. Courty, A. PrinaMello, M. Stapf, R. Ludwig, Y. Volkov, A. Latorre, Á. Somoza, R. Miranda, I. Hilger, The phenotype of target pancreatic cancer cells influences cell death by magnetic hyperthermia with nanoparticles carrying gemicitabine and the pseudo-peptide NucAnt, Nanomedicine: Nanotechnology, Biology and Medicine, 20 (2019) 101983. 
[84] L. Chen, Y. Wu, H. Wu, J. Li, J. Xie, F. Zang, M. Ma, N. Gu, Y. Zhang, Magnetic targeting combined with active targeting of dual-ligand iron oxide nanoprobes to promote the penetration depth in tumors for effective magnetic resonance imaging and hyperthermia, Acta Biomater, 96 (2019) 491-504.

[85] G.N.A. Rego, J.B. Mamani, T.K.F. Souza, M.P. Nucci, H.R.D. Silva, L.F. Gamarra, Therapeutic evaluation of magnetic hyperthermia using Fe3O4-aminosilane-coated iron oxide nanoparticles in glioblastoma animal model, Einstein (Sao Paulo), 17 (2019) eAO4786. 